\title{
Avoidance Behavior Can Function as a Negative Occasion Setter
}

\author{
Jan De Houwer and Geert Crombez \\ Ghent University
}

\author{
Frank Baeyens \\ University of Leuven
}

\begin{abstract}
The authors put forward the hypothesis that avoidance learning can result from the fact that participants learn (a) that a stimulus is followed by an unconditioned stimulus (US) when the avoidance behavior is not emitted and (b) that the stimulus is not followed by the US when the avoidance behavior is emitted. As such, avoidance behavior is assumed to function as a negative occasion setter. The results of a contingency judgment experiment involving 65 students showed that avoidance behavior indeed has the unique functional properties of a negative occasion setter (resistance to counterconditioning and selective transfer of modulation).
\end{abstract}

In studies on avoidance learning, a stimulus A is followed by an aversive unconditioned stimulus (US; A-US) unless a certain behavior $\mathrm{X}$ is emitted (A-X-USabsent). For instance, dogs in a shuttle box can receive an electric shock (US) after a light is turned on (A) unless they jump across a hurdle (X) into another chamber of the shuttle box (e.g., Solomon \& Wynne, 1953). The search for the mechanisms that drive this type of learning was at the center of learning psychology for decades. Since the 1970s, however, interest in avoidance learning has waned. This is surprising because many issues still need to be resolved. For example, little or no research has been done on avoidance learning in humans. The aim of this article is to increase the theoretical understanding of avoidance learning in humans and, more specifically, to propose a new cognitive theory that stresses the parallel between avoidance learning and occasion setting (see Holland, 1992, for a review of the literature on occasion setting).

At a structural level, avoidance learning involves a feature negative discrimination: stimulus $\mathrm{A}$ is followed by the US when feature X (i.e., the avoidance behavior) is absent, whereas A is not followed by the US when feature $\mathrm{X}$ is present. From this structural perspective, the crucial events in studies on avoidance learning are identical to those in studies on negative occasion setting. The main difference is that in the former, feature $\mathrm{X}$ is a behavior, whereas in the latter, feature $\mathrm{X}$ is a stimulus (e.g., a light). Given this structural similarity, we examined whether avoidance behavior can also assume the function of a negative occasion setter.

At a functional level, an occasion setter signals when a stimulus A will be followed by a US. In the case of a negative occasion setter, organisms learn that its presence signals that A will not be followed by the US whereas its absence signifies that A will be followed by the US. Whether a stimulus functions as a negative occasion setter can be tested by examining the way in which it

Jan De Houwer and Geert Crombez, Department of Psychology, Ghent University, Ghent, Belgium; Frank Baeyens, Department of Psychology, University of Leuven, Leuven, Belgium.

We thank Roel Custers for his help with collecting the data.

Correspondence concerning this article should be addressed to Jan De Houwer, Department of Psychology, Ghent University, Henri Dunantlaan 2, B-9000, Ghent, Belgium. E-mail: Jan.DeHouwer@UGent.be modulates conditioned responding. Studies on negative occasion setting have shown that conditioned responding to $\mathrm{A}$ is stronger when a stimulus feature $\mathrm{X}$ is absent than when this stimulus feature $\mathrm{X}$ is present. That is, the feature modulates conditioned responding to A. More important, occasion setters have two unique functional properties. First, the extent to which they modulate responding to A is independent of their own direct association with the US. Studies have shown that after feature negative training, conditioned responding to $\mathrm{A}$ is stronger when $\mathrm{X}$ is absent than when $\mathrm{X}$ is present, regardless of whether there are trials on which $X$ on its own is followed by the US (e.g., Holland, 1991). In other words, negative occasion setting is resistant to counterconditioning. Second, negative occasion setters not only modulate responding to the stimulus with which they were trained but also responding to other stimuli, especially those that have also been involved in feature negative training. That is, the modulatory power of negative occasion setters transfers selectively to other stimuli. Assume, for instance, that $\mathrm{A}$ is followed by the US unless feature $\mathrm{X}$ is present, that $\mathrm{B}$ is followed by the US unless feature $\mathrm{Y}$ is present, that $\mathrm{C}$ is followed by the US on half of the trials in which $\mathrm{C}$ is present, and that all types of trials are presented equally often. Selective transfer would imply that $\mathrm{X}$ modulates responding to $\mathrm{B}$ more than to $\mathrm{C}$ (e.g., Holland, 1989).

To test whether avoidance behavior can function as an occasion setter, we examined (a) whether avoidance behavior can modulate conditioned responding to stimuli (trained modulation), (b) whether this modulation is independent of the extent to which the behavior itself is associated with the US (resistance to counterconditioning), and (c) the extent to which transfer of modulation is selective (selectivity of transfer). We tested these predictions in the following manner (see Table 1 for a summary of the design). During a first phase, both stimulus A on its own and stimulus B on its own were always followed by a US. A third stimulus, stimulus $\mathrm{C}$, was followed by the US on only half of the trials on which it was present. During the second phase, the (human) participants again saw trials with $\mathrm{A}, \mathrm{B}$, or $\mathrm{C}$, but were now given the opportunity to press key $X$ after the presentation of stimulus $\mathrm{A}$ and to press key $Y$ after the presentation of stimulus B. Key $X$ was not available after stimulus B, key $Y$ was not available after stimulus A, and neither was available after stimulus C. Stimulus A was followed by the US unless the participant pressed key $X$. Likewise, 
Table 1

Summary of the Design

\begin{tabular}{llll}
\hline Phase 1 & \multicolumn{1}{c}{ Phase 2 } & \multicolumn{1}{c}{ Phase 3 } & Test \\
\hline A-US & A-X-USabsent ${ }^{\mathrm{a}}$ & A-US & A? \\
B-US & B-Y-USabsent ${ }^{\mathrm{a}}$ & B-US & B? \\
C-US & C-US & A-X-USabsent ${ }^{\mathrm{a}}$ & C? \\
C-USabsent & C-USabsent & B-Y-USabsent ${ }^{\mathrm{a}}$ & AX? \\
& & C-US & BX? \\
& & C-USabsent & CX? \\
& & X-US & AY? \\
& & BY? \\
& & CY? \\
& & & X? \\
& & & \\
\hline
\end{tabular}

Note. $\quad$ US $=$ unconditioned stimulus.

${ }^{\text {a }}$ The US was absent only if the participants pressed the appropriate key $(X$ or $Y$ ).

stimulus B was followed by the US unless key $Y$ was pressed. During the third phase, all events of both Phase 1 and Phase 2 were repeated in a random order. There were also additional trials on which no stimulus was presented and participants were asked to press key $X$. After they pressed key $X$, the US always occurred. At the end of the experiment, participants completed a test phase during which they were asked to imagine 11 different situations in which a certain stimulus was present and/or a certain key was pressed. No information was given about the presence of the US. Instead, for each situation participants were asked to rate how likely it was that the US would be present.

If avoidance behavior functions as a negative occasion setter, it should modulate the extent to which the US is expected. This modulation should be particularly strong for the stimulus with which a particular avoidance behavior was trained. Therefore, we predicted that US-expectancy ratings would be lower in situations with stimulus $\mathrm{A}$ and response $\mathrm{X}$ and situations with stimulus $\mathrm{B}$ and response $\mathrm{Y}$ than in situations with just stimulus $\mathrm{A}$ or stimulus $\mathrm{B}$ (trained modulation). Moreover, if the avoidance behavior functions as a negative occasion setter, trained modulation should be resistant to counterconditioning. That is, response $\mathrm{X}$ should modulate responses to $\mathrm{A}$ to the same extent that $\mathrm{Y}$ modulates responses to $\mathrm{B}$ even though $\mathrm{X}$ but not $\mathrm{Y}$ was paired with the US when presented on its own. Finally, the avoidance behaviors $\mathrm{X}$ and $\mathrm{Y}$ should also modulate responding to stimuli with which they were not trained and more so for stimuli that were also involved in avoidance training. That is, transfer should be selective. We tested this by comparing the extent to which $\mathrm{X}$ modulated responding to $\mathrm{B}$, and $\mathrm{Y}$ modulated responding to $\mathrm{A}$, with the extent to which $\mathrm{X}$ and $\mathrm{Y}$ modulated responding to $\mathrm{C}$.

In most studies on avoidance learning, highly aversive USs such as intense electric shocks are used. For ethical and practical reasons, such USs cannot be used in research with humans. We used the following two types of USs: (a) the letter $X$ written in red ink (neutral US) and (b) an aversive electrocutaneous stimulus that the participants described as clearly unpleasant but bearable (aversive US). This allowed us to test the generality of our findings. Moreover, at a practical level, neutral USs are much easier to use than aversive USs, especially in research with humans. If we find equivalent results for neutral and aversive USs, this would provide some empirical justification for the use of neutral USs in future studies on avoidance learning in humans.

\section{Method}

\section{Participants}

Sixty-five psychology students at Ghent University participated in exchange for course credits or were paid $€ 7$ (approximately U.S.\$9) for their help; 34 were assigned to the condition with neutral USs; 31 were assigned to the condition with aversive USs

\section{Stimuli and Materials}

The experiment was controlled by a custom-made Turbo Pascal 5.0 program that operated in graphics mode and was run on an IBMcompatible 486 computer with a 14-in. screen. As stimuli, we used a white circle, triangle, and square, each $2 \mathrm{~cm} \times 2 \mathrm{~cm}$. In the neutral US condition, the US was a $2 \mathrm{~cm} \times 2 \mathrm{~cm}$ red $X$. In the aversive US condition, the US was a transcutaneous electrocutaneous stimulus, delivered by an alternating current (AC) stimulator with an internal frequency of $50 \mathrm{~Hz}$. The stimuli were delivered by two Fukuda standard $\mathrm{Ag} / \mathrm{AgCl}$ electrodes (1-cm diameter) that were attached to the nondominant forearm. The skin at the electrode sites was first abraded with a peeling cream to reduce skin resistance. The intensity of the electrocutaneous stimulus was determined for each participant separately before the experiment.

Visual stimuli were presented in the center of a frame that was $20 \mathrm{~cm} \times$ $13 \mathrm{~cm}$ and that appeared at the center of the computer screen. At the top of the frame, a second frame was drawn that was $9 \mathrm{~cm} \times 1.5 \mathrm{~cm}$. In this second frame, a message could appear about the key that was available on that trial. A third frame was $5 \mathrm{~cm} \times 1.5 \mathrm{~cm}$ and was drawn at the bottom of the main frame. In this third frame, a $2 \mathrm{~cm} \times 0.5 \mathrm{~cm}$ blue or green bar appeared after the participant had given a valid response. As avoidance responses, the participants could press a blue or green key. These were the keys $D$ and $K$ of the AZERTY keyboard that was connected to the computer. Participants entered their ratings by typing in a number between 0 (very unlikely) and 100 (very likely). All instructions and messages were presented in Dutch.

\section{Procedure}

Participants took part one by one in a dimly lit room. After signing an informed consent form, they were seated in front of the computer at a distance of approximately $60 \mathrm{~cm}$ from the screen. Participants who were assigned to the aversive US condition were connected to the AC stimulator. In accordance with ethical guidelines, participants were informed that they would receive electric shocks during the experiment and that they were free to terminate the experiment at any given time. Before the start of the actual experiment, each participant in the aversive US condition was asked to select a shock intensity that he or she experienced as clearly unpleasant but bearable.

Participants in both conditions then read instructions that were presented on the computer screen. Their main task was to prevent a red $X$ (neutral US condition) or a shock (aversive US condition) from being presented. They could do this by pressing certain keys that would, however, be effective only occasionally. Sometimes, they would also be required to press a key. Finally, they were told that at the end of the experiment, there would be a test of what they had learned about the conditions under which the red $X$ (neutral US condition) or the shock (aversive US condition) were presented. After the participant had read the instructions, the experimenter demonstrated how the responses should be executed. On these practice trials, no stimuli were presented, and the only available key was the spacebar. 
Learning trials started after participants indicated that they understood the instructions. During the first learning phase, there were four trials on which stimulus $\mathrm{A}$ and the US were presented (A+ trials), four trials on which stimulus $\mathrm{B}$ and the US were presented (B+ trials), two trials on which stimulus $\mathrm{C}$ and the US were presented $(\mathrm{C}+$ trials), and two trials on which stimulus $\mathrm{C}$ only was presented $(\mathrm{C}-$ trials). Which shape (circle, triangle, or square) was assigned to which stimulus (A, B, or C) was determined randomly at the start of the experiment for each participant separately. On all trials, the shape appeared in the center of the main frame $1,500 \mathrm{~ms}$ after the onset of the frame and remained on the screen for 2,000 $\mathrm{ms}$. If the neutral US was presented, it appeared in the center of the screen 3,000 $\mathrm{ms}$ after the shape had disappeared and remained on the screen for $1,500 \mathrm{~ms}$. During that time, 10 tones of decreasing frequency were presented for $100 \mathrm{~ms}$ each, indicating failure. When the neutral US was not presented, 10 tones of increasing frequency were presented for $100 \mathrm{~ms}$ each, indicating success. The tones were added to increase the likelihood that participants registered the presence or absence of the US and to give feedback about their success in avoiding the presentation of the US. In the aversive US condition, an electrocutaneous stimulus was presented as the US. The intensity of this stimulus corresponded to the intensity that the participant selected at the start of the experimental session. It was presented for only $500 \mathrm{~ms}$, during which no tones were presented. For practical reasons, the decreasing tones were presented only after the end of the electrocutaneous stimulus. The (US-present and US-absent) trials in neutral US and aversive US conditions were identical in all other respects. In both conditions, the intertrial interval was $5,000 \mathrm{~ms}$. As was the case in all phases of the experiment, the order in which trials were presented was determined randomly for each participant separately. Note that neither the blue nor the green key were available in Phase 1.

The second learning phase started immediately after Phase 1. During this phase, there were four trials on which stimulus A was presented and key $X$ was available (AX trials), four trials on which stimulus B was presented and key $Y$ was available (BY trials), two trials on which stimulus $\mathrm{C}$ and the US was presented $(\mathrm{C}+$ trials), and two trials on which stimulus $\mathrm{C}$ only was presented ( $\mathrm{C}-$ trials). Whether the blue or green key functioned as key $X$ or key $Y$ was determined randomly at the start of the experiment for each participant separately. The $\mathrm{C}+$ and $\mathrm{C}-$ trials were identical to those of the first phase. The $\mathrm{AX}$ and $\mathrm{BX}$ trials were also identical to the $\mathrm{A}+$ and $\mathrm{B}+$ trials of Phase 1 except on the following points. First, the message "Blue key is available" or "Green key is available" appeared on the screen immediately after the shape disappeared and remained on the screen for $2,000 \mathrm{~ms}$. If the available key was pressed during this time, a confirmation bar in the corresponding color appeared on the screen for 1,000 ms, and the trial ended in the same way as a US-absent trial (see above). If the participant did not press the available key, pressed the available key before or after the message was on the screen, or pressed another key that was not available, the confirmation bar was not presented and the trial ended as a US-present trial (see above).

The third learning phase came immediately after the second one. During this phase, participants saw four $\mathrm{A}+$, four $\mathrm{B}+$, four $\mathrm{AX}$, four $\mathrm{BY}$, four $\mathrm{C}+$, and four $\mathrm{C}-$ trials. These trials were identical to the corresponding trials of Phases 1 and 2. There were also eight $\mathrm{X}+$ trials. On these trials, no stimulus was presented. Instead, the message "Press the $X$ key" (where $X$ was replaced by "blue" or "green" depending on whether the blue or green key had the function of key $X$ ) appeared for 2,000 ms in the center of the main frame $3,500 \mathrm{~ms}$ after the onset of that frame. If the participant pressed the indicated key during this time, a confirmation bar of the appropriate color was presented for $1,000 \mathrm{~ms}$, and the trial ended in the same way as other trials on which a US was presented. If the participant did not press the indicated key, the message was replaced by the message "You need to press the $X$ key in order to continue" (where $X$ was again replaced by the appropriate color). This message was accompanied by tones of 200 $\mathrm{Hz}$ that were each presented for $200 \mathrm{~ms}$ at intervals of $500 \mathrm{~ms}$. The message disappeared and the tones stopped only after the participant had pressed the appropriate key. The trial then ended in the same way as other US-present trials. To check whether participants behaved according to the instructions (e.g., did not press keys that were not available) and responded differently on A and B trials (on which a response was not available) than on AX and BY trials (on which a response was available), we registered on each trial whether participants pressed a key when no key was available and whether they did press the available key at the time it was available.

After all learning trials had been presented, instructions appeared on the screen that informed the participants about the upcoming test phase. Participants were told that 11 different situations would be described and were asked to indicate how likely it was that a red $X$ (neutral US condition) or a shock (aversive US condition) would be presented in such a situation. They could do this by entering a score between 0 (very unlikely) and 100 (very likely). Participants were told that they would not receive feedback about whether the US would be presented in the situation that was described. They were also informed that after entering a score, they would be asked to indicate how certain they were that their score was accurate by entering a second score with a value between 0 (very uncertain) and 100 (very certain). These confidence ratings were added for exploratory reasons and are not discussed further here. The 11 test situations can be found in Table 1. On each test trial, a description of the situation appeared at the top of the screen. For situations in which a stimulus and a response were present, the description read "How likely is it that a US will be presented if a [name of shape] appears and you press on the [color of key] key?" When only a stimulus was present, the description read "How likely is it that a US will be presented if a [name of shape] appears and you do not press on a key?" When only a response was present, the following description was used: "How likely is it that a US will be presented if a shape does not appear and you press the [color of key] key?" The description and rating scales disappeared after the participants entered their confidence rating. The next test trial started $500 \mathrm{~ms}$ later. The order of the test trials was determined randomly for each participant separately.

\section{Results}

One participant in the aversive US condition opted to end the session after he was told that shocks would be presented. The other 64 participants completed the experiment. In the aversive US condition, the mean individually selected intensity of the electrocutaneous stimulus was $1.76 \mathrm{~mA}$ (range 0.95-3.15 mA). An inspection of the responses emitted during the learning phase showed that the participants understood and followed the instructions. ${ }^{1}$ Because initial analyses of the test data failed to show any impact of the type of US (neutral or aversive), all $F$ s and $t$ s were less than 1, this variable was dropped from the analyses. Unless indicated otherwise, all the effects that were significant for the total group were also significant in each of the two conditions.

\footnotetext{
${ }^{1}$ We calculated the percentage of trials on which no key was available but participants nevertheless pressed a key. This happened on only $3.85 \%$ of all trials. During the third phase, participants pressed the available key on $90 \%$ of the AX and BY but pressed a key on only $6 \%$ of the A and B trials. An ANOVA with type of trial (A and B vs. AX and BY) as within-subjects variable, condition as between-subjects variable, and number of keypresses as dependent variable revealed a main effect of type of trial, $F(1,62)=1,076.36, p<.001$, but no main effect of condition or interaction $(F \mathrm{~s}<1)$. All participants pressed the available key on at least one AX trial and one BY trial and thus experienced that the US was not presented on these trials if the appropriate avoidance behavior was emitted.
} 


\section{Trained Modulation}

We calculated the mean of the difference between the US expectancy rating on the $\mathrm{A}$ and the $\mathrm{AX}$ test trials and the difference between the rating on the $\mathrm{B}$ and the $\mathrm{BY}$ test trials (i.e., [(A $\mathrm{AX})+(\mathrm{B}-\mathrm{BY})] / 2)$. One sample $t$ test showed that this modulation index was significantly larger than zero, $M=56, S D=38$, $t(63)=11.78, p<.001$.

\section{Counterconditioning of Trained Modulation}

To examine whether the $\mathrm{X}+$ trials reduced trained modulation, we compared the difference between the US expectancy on A versus AX trials with the difference between US expectancy on B versus $B Y$ trials. We calculated a counterconditioning index that corresponded to the difference between these two differences (i.e., $[\mathrm{B}-\mathrm{BY}]-[\mathrm{A}-\mathrm{AX}])$. The counterconditioning index did not differ from zero, $M=6, S D=34, t(63)=1.32$. Nevertheless, participants did expect the US to a greater extent on $\mathrm{X}$ test trials than on $\mathrm{Y}$ test trials, $t(63)=8.07, p<.001$ (see Table 2 ).

\section{Transfer of Modulation}

In order for trained modulation to transfer, it is logically necessary that trained modulation is present in the first place. In all our analyses of transfer of modulation, we therefore only took into account the data of participants who had a modulation index greater than zero. This resulted in the removal of the data of 7 participants ( 4 in the neutral US condition and 3 in the aversive US condition). We first examined whether trained modulation transferred to stimuli that were involved in avoidance training. To this end, we calculated a first transfer index that corresponded to the mean of the difference between the US expectancy rating on A and $\mathrm{AY}$ trials and the difference between the US expectancy rating on $\mathrm{B}$ and $\mathrm{BX}$ trials (i.e., $[(\mathrm{A}-\mathrm{AY})+(\mathrm{B}-\mathrm{BX})] / 2)$. This index was significantly different from zero, $M=33, S D=37, t(56)=6.83$, $p<.001$. Although significant transfer thus occurred, it was not perfect: The trained modulation index was significantly larger than

Table 2

Mean US Expectancy Ratings as a Function of Test Trial and Condition

\begin{tabular}{|c|c|c|c|c|}
\hline \multirow[b]{3}{*}{ Test trial } & \multicolumn{4}{|c|}{ Condition } \\
\hline & \multicolumn{2}{|c|}{ Neutral US } & \multicolumn{2}{|c|}{ Aversive US } \\
\hline & $M$ & $S D$ & $M$ & $S D$ \\
\hline A & 75 & 26 & 81 & 22 \\
\hline B & 74 & 27 & 79 & 26 \\
\hline $\mathrm{C}$ & 53 & 24 & 54 & 24 \\
\hline $\mathrm{AX}$ & 27 & 32 & 23 & 32 \\
\hline $\mathrm{BX}$ & 48 & 38 & 55 & 40 \\
\hline $\mathrm{CX}$ & 38 & 26 & 46 & 37 \\
\hline AY & 42 & 31 & 54 & 39 \\
\hline BY & 20 & 28 & 15 & 27 \\
\hline CY & 37 & 26 & 40 & 33 \\
\hline$X$ & 76 & 33 & 76 & 34 \\
\hline $\mathrm{Y}$ & 30 & 30 & 36 & 35 \\
\hline
\end{tabular}

Note. $\quad$ US $=$ unconditioned stimulus. the transfer of modulation index, $t(56)=5.49, p<.001$. We also examined transfer of modulation for stimuli that were not involved in avoidance training by calculating a second transfer of modulation index, this time for stimulus $\mathrm{C}$ (i.e., $[(\mathrm{C}-\mathrm{CX})+(\mathrm{C}-$ $\mathrm{CY})] / 2$ ). Transfer of modulation for stimulus $\mathrm{C}$ was significant, $M=15, S D=32, t(57)=3.57, p=.001$, but only marginally so in the aversive US condition, $t(26)=1.91, p=.07$. Again transfer was submaximal, $t(57)=9.77, p<.001$.

To examine whether transfer was selective, we compared the transfer of modulation for stimuli that were involved in avoidance training (i.e., A and B) with transfer of modulation for stimulus $\mathrm{C}$ that was not involved in such training. Because US expectancy ratings were lower on $\mathrm{C}$ test trials than on $\mathrm{A}$ and $\mathrm{B}$ test trials, $t(63)=6.39, p<.001$ (see Table 2), the maximal extent to which the presence of an avoidance behavior could lower the US expectancy was smaller for stimulus $\mathrm{C}$ than for stimuli $\mathrm{A}$ and $\mathrm{B}$. We therefore calculated the proportion rather than absolute level of modulation for stimulus $\mathrm{C}$ and compared it with the proportion of modulation for stimuli A and B. First, we subtracted the mean of the US expectancy rating on both the $\mathrm{CX}$ and $\mathrm{CY}$ trials from the US expectancy rating on $\mathrm{C}$ test trials. We then divided both differences by the US expectancy rating on $\mathrm{C}$ test trials (i.e., $[([\mathrm{C}-\mathrm{CX}] / \mathrm{C})+([\mathrm{C}-\mathrm{CY}] / \mathrm{C})] / 2)$. A similar relative transfer of modulation index was calculated for stimulus $A$ (i.e., $[\mathrm{A}-\mathrm{AY}] / \mathrm{A}$ ) and stimulus $\mathrm{B}$ (i.e., $[\mathrm{B}-\mathrm{BX}] / \mathrm{B}$ ) and the mean of these two relative scores was compared with the relative transfer index for stimulus $\mathrm{C}$. There was one participant in the aversive US condition who gave a rating of zero on the $\mathrm{C}$ test trial and for which a relative transfer index could thus not be calculated for stimulus C. A paired-samples $t$ test showed that the relative transfer index for $\mathrm{C}$, $M=.12, S D=.81$, was significantly lower than that for A and $\mathrm{B}$, $M=.35, S D=.51, t(55)=2.02, p<.05$. This demonstrates that transfer of modulation was selective. ${ }^{2}$

\section{Discussion}

On the basis of the structural similarity of the events in avoidance learning and the events in negative occasion setting, we put forward the hypothesis that avoidance behavior can function as a negative occasion setter. As predicted, the results showed (a) that avoidance behavior modulated the extent to which the US was expected after the stimulus with which the behavior was trained (i.e., trained modulation), (b) that this trained modulation was

\footnotetext{
${ }^{2}$ The relative transfer indices were not significantly different in the neutral US condition, $t(29)=1.59, p=.12$, nor in the aversive US condition, $t(25)=1.23, p=.23$. Note, however, that when we excluded participants who did not give a lower rating on the $\mathrm{C}$ test trials than on the $\mathrm{A}$ and $\mathrm{B}$ test (and who thus did not pick up on the fact that the contingency was different on the $\mathrm{C}$ training trials [contingency of .50] than on the $\mathrm{A}$ and $\mathrm{B}$ training trials [contingency of 1]), the relative transfer index for $\mathrm{C}$ was significantly lower than the relative transfer index for A and B in the neutral US condition, $t(18)=2.47, p=.02$, and marginally so in the aversive US condition, $t(22)=1.94, p=.07$. Excluding these participants can be justified because one could argue that they did not pay enough attention to the task or incorrectly believed that $\mathrm{C}$ was entirely equivalent to A and B (i.e., that all three stimuli are followed to the same extent by the US in the absence of a behavior), in which case transfer of modulation for $\mathrm{C}$ should be as strong as transfer of modulation of A and B.
} 
unaffected by whether the behavior itself was followed by the US on separate trials (i.e., trained modulation was resistant to counterconditioning of the behavior), (c) that an avoidance behavior also modulated expectation of the US in the presence of stimuli with which it did not co-occur previously (i.e., transfer of modulation), and (d) that this transfer of modulation was more pronounced for stimuli that were also involved in avoidance training than for those that were not (i.e., selective transfer of modulation). We can thus conclude that avoidance behavior can function as a negative occasion setter.

This conclusion has important implications for our understanding of avoidance learning. It supports an occasion setting account according to which organisms learn (a) that $\mathrm{A}$ is followed by the US when behavior $\mathrm{X}$ is not emitted and (b) that $\mathrm{A}$ is not followed by the US when behavior $\mathrm{X}$ is emitted. An occasion setting account thus implies that organisms make avoidance responses because they have learned that these responses determine the relation between the warning stimulus and the US. This account is akin to the cognitive account of avoidance learning that was suggested by Seligman and Johnston (1973). They postulated that avoidance behavior is based on essentially two expectations that the organism acquires during the learning task: The animal learns (a) that the US will be present if behavior $\mathrm{X}$ is not emitted under certain conditions (e.g., when stimulus $\mathrm{A}$ is present) and (b) that the US will not be presented if $\mathrm{X}$ is emitted under certain conditions (e.g., after the onset of A). Because the US is aversive, organisms will use these expectancies to try to avoid the US. Although the occasion setting account and the cognitive account of Seligman and Johnston both postulate that avoidance learning is based on the formation of expectancies, the latter account focuses on knowledge about the X-US relation rather than the A-US relation. Avoidance behavior is thus seen as something that prevents the US under certain conditions rather than as something that signals when the warning signal will or will not be followed by the US.

It is important to note that the cognitive account of Seligman and Johnston (1973) does not predict that avoidance behavior can have all the functional properties of an occasion setter. Assuming that expectancies about the X-US relation are strictly context dependent (i.e., valid only when stimulus A is present), one could argue that the cognitive theory predicts that trained modulation will be resistant to counterconditioning. Trials on which behavior $\mathrm{X}$ is emitted in the absence of A are indeed irrelevant for expectancies in situations in which $\mathrm{X}$ is emitted in the presence of $\mathrm{A}$. But in that case, the cognitive theory does not predict that modulation should transfer selectively. It would predict that modulation will not transfer at all because the crucial expectancies are assumed to be specific to certain situations. One could argue that expectancies are not entirely specific to a certain situation but that they generalize to a certain extent to similar situations. Note, however, that although this auxiliary assumption would help the model to explain transfer of modulation, it would also imply that trained modulation should be sensitive to counterconditioning. Moreover, even with this auxiliary assumption, the model would not predict that transfer will be selective.

We are also unaware of any other model of avoidance learning that would predict that avoidance behavior can function as a negative occasion setter. Traditional two-factor theories (e.g., Mowrer, 1947; see McAllister \& McAllister, 1991, for a review) regard avoidance behavior as being elicited by the warning signal $\mathrm{A}$ as the result of acquired stimulus-response (S-R) associations. These associations are formed and strengthened initially because the avoidance behavior results in the removal of the US that occurred in the context of the warning signal A. When the US is afterward successfully avoided, the S-R associations (and thus avoidance behavior) are maintained because the avoidance behavior is followed by a reduction of the conditioned fear. In these models, expectancies play no role. Traditional two-factor theories are therefore silent about whether avoidance behavior would modulate the extent to which the US is expected in the presence of certain stimuli, let alone that this modulation should be resistant to counterconditioning and should transfer selectively. Expectancies are important in cognitive variants of the two-factor theory (see Gray, 1987) that are in some respects quite similar to the cognitive account of Seligman and Johnston (1973). According to these models, stimuli that accompany avoidance behavior (e.g., kinesthetic feedback) become safety signals, that is, signals for the absence of an expected US. These safety signals are assumed to reinforce the avoidance behavior. Such a view implies, however, that avoidance behavior will be affected by counterconditioning because this would counteract the reinforcement of the avoidance behavior. Moreover, it is difficult to see why transfer of modulation would be selective according to this view.

There are several important differences between our study and previous studies on avoidance learning. First, we did not use highly aversive USs. Nevertheless, the fact that we found the same results with a neutral US as with a mildly aversive US does attest to the generalizability of our findings. Second, we examined the extent to which the US was expected in imagined situations rather than analyzing actual avoidance behavior. We had several reasons to choose this course of action. First, US expectancy is crucial according to the occasion setting account that we wanted to test. Second, measuring US expectancies offers a convenient way to test various hypotheses within the same experimental session. Third, US expectancy ratings have often been used as a dependent measure in human learning research (e.g., De Houwer \& Beckers, 2002). Nevertheless, it is true that our results are relevant for understanding actual avoidance behavior only to the extent to which US expectancies actually drive avoidance behavior. It will thus be important to run an experiment similar to the present one but in which the frequency of actual avoidance behavior is used as the main dependent variable.

The events that we presented during the learning phase also differed somewhat from those that are presented in a typical study on avoidance learning. For instance, in Phase 3, we included trials on which participants were prevented from making the avoidance response and trials on which participants were forced to make an avoidance response. Such trials were included because they were necessary to test the hypotheses. However, it is possible that they also influenced the manner in which participants solved the problem. Moreover, we acknowledge that there are some findings in the literature on avoidance learning that are not easy to explain on the basis of an occasion setting account (e.g., the finding that punishment of an avoidance behavior can sometimes enhance avoidance responding in animals, see Gray, 1987). We therefore agree that our occasion setting analyses probably does not provide an exhaustive account of human avoidance learning. It might well be that avoidance behavior can be driven by a variety of mecha- 
nisms, each of which is more likely to operate in certain situations than in others. But our data clearly demonstrate that avoidance behavior can at least in some situations function as a negative occasion setter.

The reported results are also relevant for research on occasion setting. First, our results provide the first demonstration of occasion setting in which a behavior functions as the negative occasion setter. Such a finding is not surprising in the light of previous ideas about the close link between stimuli and behaviors (e.g., Premack, 1959). It is, however, the first of its kind and increases the scope of research on occasion setting. Second, we found that behavior can function as a negative occasion setter even though it occurred after the target stimulus. This appears to be at odds with the results of previous studies that showed that (negative) occasion setting is more likely to occur when the feature $\mathrm{X}$ is presented before the target stimulus A (e.g., Holland, 1992). But note that in our experiment, $\mathrm{X}$ was a behavior rather than a stimulus. The fact that $\mathrm{X}$ and $\mathrm{A}$ were clearly different may have encouraged participants to believe that $\mathrm{X}$ and $\mathrm{A}$ had a different function (i.e., the function of modulator and predictor, respectively). Third, our study is one of the few that have looked at (negative) occasion setting in humans (e.g., Baeyens, Vansteenwegen, Hermans, Vervliet, \& Eelen, 2001). As such, our data provide further evidence for the fact that findings on occasion setting in animals can be generalized to humans.

\section{References}

Baeyens, F., Vansteenwegen, D., Hermans, D., Vervliet, B., \& Eelen, P. (2001). Sequential and simultaneous feature positive discriminations: Occasion setting and configural learning in human Pavlovian conditioning. Journal of Experimental Psychology: Animal Behavior Processes, 27. 279-295.
De Houwer, J., \& Beckers, T. (2002). A review of recent developments in research and theory on human contingency learning research. Quarterly Journal of Experimental Psychology: Comparative and Physiological Psychology, 55(B), 289-310.

Gray, J. A. (1987). The psychology of fear and stress (2nd ed.). Cambridge, England: Cambridge University Press.

Holland, P. C. (1989). Transfer of negative occasion setting and conditioned inhibition across conditioned and unconditioned stimuli. Journal of Experimental Psychology: Animal Behavior Processes, 15, 311-328.

Holland, P. C. (1991). Acquisition and transfer of occasion setting in operant feature positive and feature negative discriminations. Learning and Motivation, 22, 366-387.

Holland, P. C. (1992). Occasion setting in Pavlovian conditioning. The Psychology of Learning and Motivation, 28, 69-125.

McAllister, D. E., \& McAllister, W. R. (1991). Fear theory and aversively motivated behavior: Some controversial issues. In M. R. Denny (Ed.), Fear, avoidance and phobias: A fundamental analysis. Hillsdale, NJ: Erlbaum.

Mowrer, O. H. (1947). On the dual nature of learning: A reinterpretation of 'conditioning' and 'problem solving'. Harvard Educational Review, 17, 102-148.

Premack, D. (1959). Toward empirical behavioral laws: Instrumental positive reinforcement. Psychological Review, 66, 219-233.

Seligman, M. E. P., \& Johnston, J. C. (1973). A cognitive theory of avoidance learning. In F. J. McGuigan \& D. B. Lumsden (Eds.), Contemporary approaches to conditioning and learning. Washington, DC: Winston-Wiley.

Solomon, R. L., \& Wynne, L. C. (1953). Traumatic avoidance learning: Acquisition in normal dogs. Psychological Monographs, 67(4, Whole No. 354).

Received January 30, 2004

Revision received July 27, 2004

Accepted August 20, 2004

\section{Wanted: Old APA Journals!}

APA is continuing its efforts to digitize older journal issues for the PsycARTICLES database. Thanks to many generous donors, we have made great strides, but we still need many issues, particularly those published in the 1950s and earlier.

If you have a collection of older journals and are interested in making a donation, please e-mail journals@apa.org or visit http://www.apa.org/journals/donations.html for an up-to-date list of the issues we are seeking. 